\title{
On the Use of Fluorescein in the Treatment of Leprosy
}

\author{
Jose M. M. Fernandez and Salomon Schujman.
}

I

$\mathrm{N}$ a preliminary report on the action of certain dyes in leprosy, Gordon A. Ryrie (1)-Medical Superintendent of the Federal Leper Settlement, Sungei Buloh- presents the results obtained with the use of several dyes in the treatment of leprosy.

One of the writers during his stay in the above mentioned colony, had the opportunity of talking with Ryrie about his researches and examining some patients who had apparently improved with this new method of treatment.

Desiring to have a personal opinion about the therapeutic value of such medication we have tried it on some patients in the Carrasco Hospital.

On March 1934 we started our researches trying three different kinds of dyes, trypan blue, eosin and fluorescein. In the present paper we shall report only the results obtained with the use of fluorescein.

\section{Treated Cases.}

We treated 32 patients, the majority of them being advanced cases. With the exception of three cases, all others had previously received chaulmooga oil derivatives. Clinical and bacteriological conditions of every case were carefully chanted before and after treatment. Periodically we controlled the sedimentation rate and examined smears for the M. leprae.

\section{Plan of Treatment.}

According to Ryrie's advice we prepared the following solution :-

$$
\begin{array}{cccr}
\text { Fluorescein Gübler } & \ldots & \ldots & 2 \text { grammes } \\
\text { Sodium bicarbonate } & \ldots & \ldots & 2 \text { grammes } \\
\begin{array}{c}
\text { Distilled water } \\
\text { (filtered, sterilized) }
\end{array} &
\end{array}
$$

We always used a solution freshly prepared daily which we protected against light.

We started with a dose of 5 c.c. intravenously, repeated twice a week. Afterwards we always administered 15 and even 20 c.c. twice a week without any trouble. Simultaneously with intravenous injections, we have infiltrated intra-dermally the cutaneous lesions with the same fluorescein solution repeated once a week and occasionally twice. With nearly 


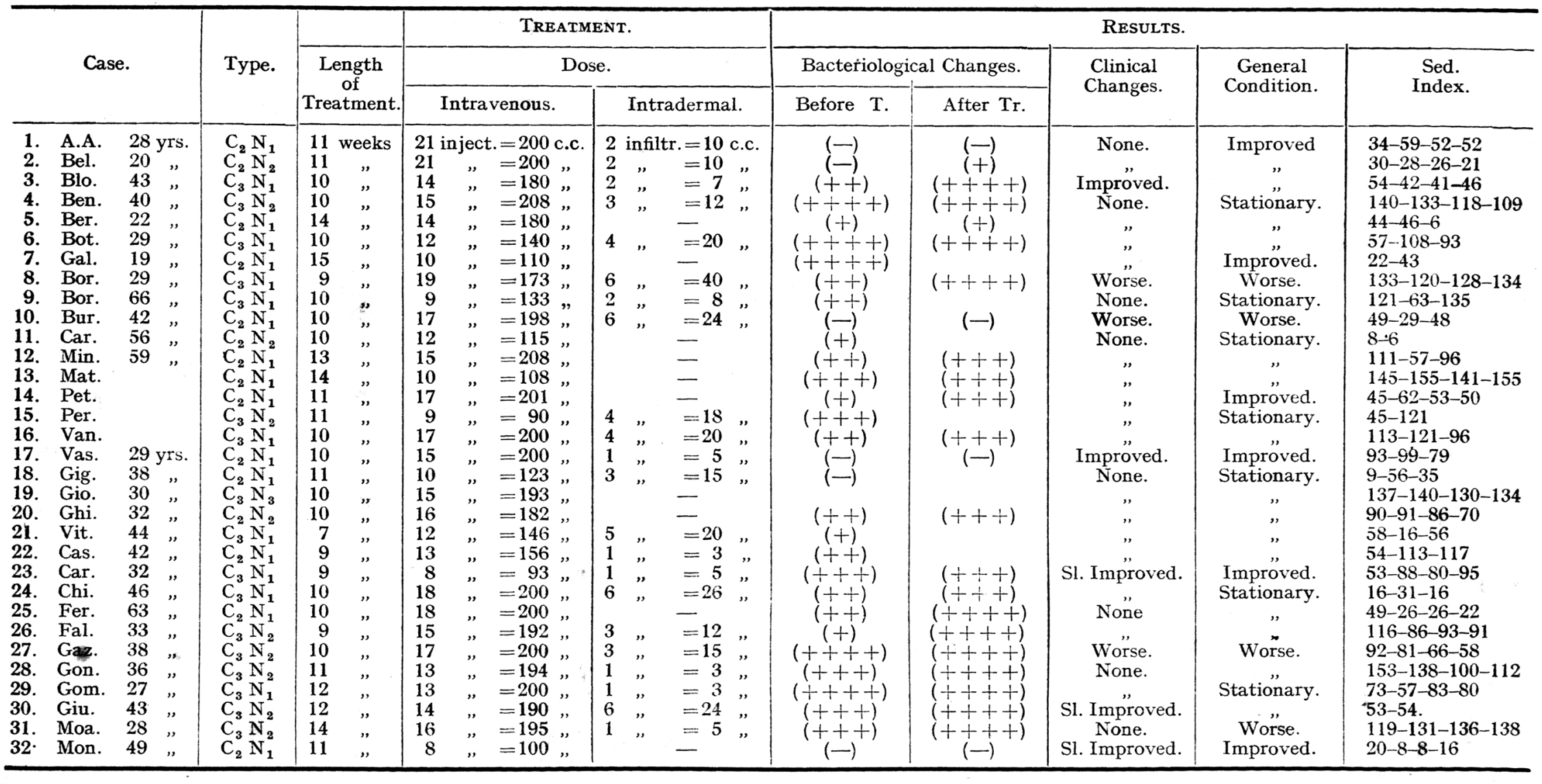


all the patients under treatment we reached a total dose of 200 c.c. in a period varying from 10 to 14 weeks.

The medication was well tolerated in every case. The only precaution we advised patients was to avoid direct sunshine immediately after the injections. Many of the treated cases were out-patients who returned home directly after the injections without any discomfort.

\section{Therapeutic Activity.}

Clinical Changes: Twenty-three out of the thirty-two cases did not show any clinical improvement when the course ended. Five cases showed a slight improvement and in only one patient the improvement was marked.

In three cases the cutaneous lesions were benefited by intradermal injections. In three other cases (ob. 10-8-17) we observed on the contrary that patients became worse, as the lesions became more infiltrated and active. In one case (ob. 10) some new lesions appeared during treatment.

Bacteriological Changes: We did not observe any favourable bacteriological change in the lesions, even in those intrademally infiltrated. On the contrary, as Ryrie states, we verified a marked rise in the bacillary content of the lesions.

Histological Changes: A histological study of the lesions was made before and after treatment of intradermal infiltration with fluorescein without noting any change.

Influence of Treatment in the General Condition: In 8 cases an improvement of the general condition was observed. The weight, strength and appetite increased. In 5 cases the general condition failed, while in all the other treated cases no change was seen.

\section{InFluence on the Complications.}

Lepra Reaction: In another paper we reported our experiences about this subject (2). We will only state here that according to our own experience, the use of fluorescein in the treatment of lepra reaction is not as encouraging as other workers assert.

Eye Complications: We have tried this dye in several cases of acute iritis with good results. We have reported in another paper (3) our experience with it.

Conclusions.

1. Using fluorescein in the treatment of leprosy according to Ryrie's method we have not obtained the favourable results observed by other workers. 
2. This treatment seems to suit certain forms of acute iritis consecutive to lepra reaction.

\section{REFERENCES.}

(1) Ryrie, Gordon A.-A preliminary report on the action of certain dyes in leprosy. Intern. Jour. of Lepr. Vol. 1, No. 4. Oct. 1933.

(2) Fernandez, J. M. M. and Schujman, S.-El empleo de las anilina en la reacción leprosa. Trans. of the V. National Congress of Medicine, Rosario, Argentine. Sept. 1934.

(3) Fernandez, J. M. M., Schujman, S. and Huber, E.-Tratamiento de las complicaciones oculares de la lepra. Trans. of the V. National Congress of Medicine, Rosario, Argentine. Sept. 1934. 